\title{
ERRATUM
}

Sabine Dormann · Marcus Krüger · Roland Hentschel

Regina Rasenack · Brigitte Strahm · Udo Kontny

Charlotte Niemeyer

\section{Life-threatening complications of transient abnormal myelopoiesis in neonates with Down syndrome}

Published online: 15 February 2005

(C) Springer-Verlag 2005

\section{Eur J Pediatr (2004) 163:374-377}

In the last paragraph of the "Discussion" section, the following sentence should read as follows:

We suggest a starting dose of Ara-C of $0.5 \mathrm{mg} / \mathrm{kg}$ per day which may be increased up to $1.5 \mathrm{mg} / \mathrm{kg}$ per day depending on the clinical condition and the $\mathrm{WBC}$ of the patient.

In the online and print versions " $\mathrm{m}^{2}$ " was inadvertently written, instead of "kg".

The online version of the original article can be found at http:// dx.doi.org/10.1007/s00431-004-1452-7

S. Dormann $(\square) \cdot$ M. Krüger $\cdot$ R. Hentschel $\cdot$ B. Strahm

U. Kontny $\cdot$ C. Niemeyer

Department of Paediatrics and Adolescent Medicine,

University of Freiburg, Mathildenstrasse 1,

79106 Freiburg, Germany

E-mail: dormann@kikli.ukl.uni-freiburg.de

Tel.: +49-761-2704506

Fax: $+49-761-2704518$

R. Rasenack

Department of Obstetrics and Gynaecology,

University of Freiburg,

Hugstetterstrasse 55, 79106 Freiburg, Germany 